\title{
Coping with Trauma: Verbatim Accounts of Victims of Police Torture in Kenya.
}

\author{
Joseph Njoroge Kinyanjui
}

\begin{abstract}
When individuals go through events that threaten their lives or the lives of those they love, it is traumatic. The trauma leaves in its wake a group of symptoms that, if not addressed, lead to Post Traumatic Stress Disorder (PTSD).

Even with PTSD's severe stress reactions, individuals have to continue-though extremely hard-functioning. How do they do it? What do they rely on to cope despite the painful condition they live with day in and day out?

This research analyzed 16 verbatim accounts of torture and highlights how these individual coped. How did they make sense of what had happened to them? What informed their resilience? It is important as it can point out what those who do not develop PTSD are doing to avoid succumbing to the disorder. We might be able to 'pick' all the coping strategies of those who did not develop PTSD and use these to teach individuals effective ways of coping with trauma.
\end{abstract}

The results of the study reveal that what people think about what happens to them as well as the attitude they adapt influences their coping strategies with the trauma. This idea could be used to teach people how to make sense of the awful events that happen to them and how to generate meaning from arbitrary and senseless events that happen and traumatize them.

Key words: PTSD, Coping, Trauma.

\section{Introduction}

Though traumatic incidents, both natural and man-made, are frequent, it is amazing that PTSD prevalence is quite low. The National Institute of Mental Health (NIMH) 2007 says that the prevalence among U.S. adults is about " $3.6 \%$ for adults between 18 to 54 " years. We think this is quite low. It would have been interesting to compare this with the prevalence here in Kenya but this researcher has not come across such information yet.

Research clearly shows that not all individuals exposed to traumatic incidents develop PTSD, (National Institute of Mental Health 2007; Silvoner2002, Helzer et al (1987;Davidson et al 1991; Keane et al 1994); Resnick et al (1993); (Kulka et al 1988)

Kulka et al 1988(as quoted in National Institute of Mental Health 2007), for instance, found a prevalence of about $30 \%$ among Vietnam War Veterans. This clearly shows that, though all the war veterans were in the same theatre of conflict not all developed PTSD as a result of it. The $70 \%$ seem to have had a more effective coping strategy 
that helped them not succumb to PTSD. What then is it that helps some people not to develop PTSD when they have all gone through the same traumatic event? Even among those who develop PTSD, some are able to deal with it better than others and are able to continue functioning while others literally 'fall apart' emotionally. This investigation aims to look at the things that "held" our victims of torture together even with PTSD and enabled them to continue living. How they managed to cope with their pain and continued shouldering their other responsibilities. This knowledge can be crystallized and replicated whenever other individuals unfortunately experience traumatic situations and events.

As Foa (1995), asserts:

Given the high rates of both traumatic events and of resulting PTSD, combined with the ever growing population of those with PTSD because of the chronicity of the disorder, it is imperative to be able to identify immediately following a trauma those who are likely to develop chronic PTSD and to develop efficacious and cost-effective treatments for these individuals. This is especially warranted given that prospective studies of trauma victims typically reveal higher rates of PTSD. p.499

Those who do not develop PTSD seem to adapt to the trauma by 'getting' on a trajectory that puts them on a path to health. Bonanno (2004) talks about individuals who experience trauma exhibiting different trajectories; those who cope favorably with trauma are on a different trajectory than those who do not. This is how Bonanno (2004) puts it:

The author challenges these assumptions by reviewing evidence that resilience represents a distinct trajectory from the process of recovery. P.20

An individual recovering from trauma at first experiences high stress levels even PTSD, sometimes followed by the gradually disappearance of the PTSD symptoms. The individual, who is resilient however, might experience elevated stress levels immediately after the trauma but does not succumb to PTSD. S/He slowly regains normal functioning. Bonanno et al (2005) put it this way:

These trajectories included a stable low-symptom trajectory indicative of resilience, an initial elevation of symptoms followed by a decline in symptoms over time indicative of recovery. P.986

As Foa (1995) argues above, if we could identify what helps some individuals not succumb to PTSD, we might use this information to help those who do so. Similarly, if we could identify the characteristics of individuals who adopt a resilient trajectory after a traumatic event Bonanno et al (2005), we could be able to help those who succumb to those traumatized.

We will look at a set of 16 verbatim accounts of victims of police brutality, their subsequent traumatization and what they thought, felt, behaved or believed to help them keep 'putting one leg after another' as they continued with the struggles of daily living. 


\section{Problem Statement}

When individuals go through traumatic events, their reactions to the events and subsequent development of PTSD vary from one individual to the next. Even among those who go through highly stressful events, such as a lingering illness followed by the death of a loved one, (Schut et al 1991) assert that only $50 \%$ of the victims develop PTSD. Clearly, the other half that does not have a way of coping. Aldwin et al (1994) agree and explain that it has to do with how individuals cope with the trauma. Those who are more resilient do not develop the psychological and physical reactions. This is how they put it:

Stress is ubiquitous. It is unavoidable, occurs in myriad contexts and can have deleterious effects, both psychological and physical. However, it is clear that some individuals are more resilient to stress than others. P.34

How do they do it? Is it the thoughts, feelings, attitudes and beliefs that they harbor that gives them this resilience or what is it? We intend to highlight the thoughts, beliefs, attitudes and behaviors that some victims of police torture had. Could this have helped them survive their ordeal? If they never behaved this way, would they have collapsed emotionally resulting in them not being able to function adequately in society?

What makes some individuals more resilient than others? Is it their thoughts, attitudes or behavior? Some of the people arrested with the subjects we interviewed died while others lost their minds. These are the questions that we will be grappling with in this research. What informed the resilience of those who survived is what we want to explore in this research.

\section{Conceptual framework}

One of the characteristics of an event that makes it affect individuals severely is the severity of exposure to the event (Silver et al 2002). If one is at the epicenter of the event, they will get affected more severely than those on the periphery. Psychologist Roxane Silver has studied the effects of the 9/11/01 terrorist attacks on New York City and Washington, D.C. Her research focused on the immediate and long-term responses to the attacks and found that the severity of exposure to the event, rather than the degree of loss, predicted the level of distress among people. For example, people who reported seeing the planes smash into the trade center buildings experienced more PTSD symptoms than average, but people who experienced financial losses because of the attacks did not.

Other studies have shown that simply watching traumatic events on TV can be traumatic to some, especially those individuals who had pre-existing mental or physical health difficulties or had a greater exposure to the attacks. 
Unpredictability or arbitrariness of the traumatic event is another contributor to severe traumatization of individuals. Dr. Abu Tawahina, who worked with families of suicide bombers says the fact that the families did not know in advance made things worse. He says that none of the families knew in advance that their family member was going to participate or be involved in such an act. "That's what makes the trauma worse-it's not predictable,"... Could it be that the arbitrariness of the attack evoked a sense of powerlessness in the individuals resulting in feelings of not being in control?

Yet, Bonanno et al (2005) interviewed individuals near or in the World Trade Center during the September 112001 terrorist attack and found some who did not develop PTSD symptoms. How did this happen when the researchers above support the notion that proximity to the event would almost certainly ensure PTSD? It is this phenomenon that we want to investigate. It seems some individuals can withstand life threatening events and still not manifest PTSD symptoms. What do they do to accomplish this? How for instance, do they perceive what is happening to them? Is it their attitude towards the event, their belief system or world-view that 'shields' them? These are some of the questions we hope this research will shed some light on.

What the victims make of the traumatic incident has a bearing. Klingler (1996) talks about culture being the 'filter' through which we see the world, as such the world view of the trauma survivor will determine a lot, we contend.

\section{Methodology}

Some fifteen victims of torture and a victim of an attack by the 'mungiki' counseled using an approach known as Multi-Sensory Trauma Processing (MTP). This involves the counselee retelling their story in as much detail as they can remember which the therapist writes down. The therapist then re-tells the story to the client while the client listens to some gentle drum sounds as $\mathrm{s} /$ he is tapped rhythmically on the shoulders.

The researcher analyzed these stories especially in answer to the question, "What was positive in the entire trauma you went through". It is in effect a question asking what sustained them in the midst of the horrendous trauma they experienced. Most were shocked by this question but when they got that we wanted to know what worked or what helped them cope during the trauma, then they were able to respond.

\footnotetext{
${ }^{1}$ These are violent tribal gangs of jobless youth created by politicians to intimidate and beat up anyone who oppose them. Allowed to extort money from businesses and though who resist have their premises burnt or get killed.
} 


\section{Joseph Njoroge Kinyanjui}

\section{Results}

An analysis of the sixteen individuals reveals the various thoughts, attitudes and world-view they adapted to help them continue 'putting one foot after the other', that is continue living. Most of them were tortured by the police: four for being suspected of engaging in crime; three for raiding a police station to steal guns and one for rape. Eleven of the others were arrested and tortured for allegedly being involved in a 'subversive' organization known as 'mwakenya'2.

Most of them underwent terrible experiences: being beaten unconscious; humiliating acts such as being interviewed while naked or a police officer of opposite sex describing the sexual organs of the victim disparagingly; being denied sleep by lying in water-logged cell for 4 to 5 days. The victims actually drank this water that they were also relieving themselves in and receiving electric shocks.

The last individual was attacked by the "mungiki" and slashed with machetes until they thought he was dead. He actually had an outer body experience, that is, at one time he could hear and see what they were doing to him, though his eyes were closed and he stopped feeling pain. Attached is an excerpt from one of the victims of police torture.

I was isolated and put in my own cell. I could hear screams as other people were beaten. They hanged me upside down by my ankles and beat me all over the body with broken table legs. I lost sense of time. I got confused. They said if I died it did not matter since there were twenty-four million Kenyans. I stayed captive for eleven days. We were given bread and water. They beat me on the soles of my feet until my skin peeled off.

After six days they mixed us with other prisoners in the cells. Then they came on the following day and blindfolded us. They took us to a forest, put hoods over our heads and asked us to say our last prayers. A shot rang out and I heard a scream. I knew they meant business.

I cannot even recall some of the people-police- who tortured me. My memory was confused. They put pins into my private parts to inflict pain. They broke my teeth. They would remind me that the body has no spare parts. I cannot remember going to the toilet.

After eleven days we were taken to court. ...

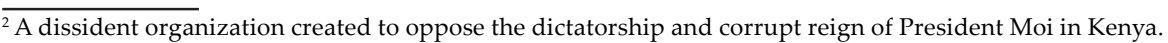


All these individuals tried to come to terms with what had happened to them in a number of ways. All of them had PTSD symptoms of varying degrees and intensity. The following are some of the strategies they used to cope:

\subsection{Reliance on a Higher Power or God}

$63 \%$ of the participants did this. They admitted to praying a lot. One was an atheist before his incarceration but he also found himself praying. As a result, they felt like whatever happened to them had a purpose -even though they did not know what this was. There was a 'bigger picture' to their experience as is expressed by these quotes; "A higher truth sustained me." "I grew spiritually."

\subsection{Positive emotions}

It is like they refused to yield to negativity. This is depicted by what some of them said, "I have not revenged even though I wanted to." "I don't feel ashamed." "I did not become bitter." "Though very hungry, I never sold myself to homosexuality." "I upheld my dignity rather than have sex with a policeman" $(38 \%)$

\subsection{A determination to survive and a feeling of vindication}

The following quotes exemplify this. "I would still stand up against violation of human rights." "I had hope because I knew I was innocent." "When you believe in something, it makes it easier to pay." "I have to get well so that I can help those still suffering." "What we suffered for inspired others to fight for the freedom we sought." "I did not suffer in vain we have a new regime" "Despite their attempts to crush my spirit, I have survived." (44\%)

\subsection{Sense of humor}

(13\%)"My sense of humor kept me going." " I give speeches to the other inmates and sometimes imagine an audience just for fun."

\section{Discussion}

What is it about these attributes that helped? What is it for instance, about believing in a Higher Power that helped sustain these individuals? If we could figure it out we might be able to teach traumatized individual how to access this 'help'. We might also be able to design instruments that may help us explain scientifically how this is happening.

These individuals remained optimistic and hopeful even though their situation was dire. Though the optimism seemed misplaced, in the face of their terrible circumstances, it helped. Taylor et al (2000) seem to agree when they assert that:

Optimism, a sense of personal control, and the ability to find meaning in one's life experiences are valuable psychological resources long believed to be associated with mental health (p. 99) 
From working with breast cancer patients, Taylor (1983) supports these findings when she says that the psychological resources are especially important when people are faced with challenging and threatening events. Our subjects were obviously faced by such events.

They harbored positive beliefs about their illness, some of which were unrealistic, yet this improved their mental health. Taylor et al (2000) state, "Positive illusions appear to have protective psychological effects generally that may become especially important in the context of severely threatening events."P.100 Bonanno et al (2005) agree based on what they call the trait of self-enhancement or "an overly positive bias about oneself", Maddi (2005). Bonanno, Rennicke and Dekel (2005) in an investigation of resilience in relation to the September 11 terrorist attack on the World Trade Center assert that,

In other words, the tendency toward biased and overly favorable perceptions of the self not only appears to help people who use such biases to cope with extremely adverse situations but also appears to help them ignore the social costs that can be engendered by that tendency.p.995

This is one of the pathways to resilience. Hardiness is another according to Bonanno (2004) who argues that there are multiple pathways to resilience. Maddi (2002) says hardy attitudes amount to courage and motivation to face stressors accurately.

Over half of the subjects relied on God to cope. This seemed to help them make sense of their circumstances as well as find a benefit from it, or what Davis, NolenHoeksema and Larson(1998) call "sense making" and "benefit-finding". They quote Dull \& Skokan, 1998, P.C Smith , Range \& Ulmer, 1992 as identifying religious and spiritual beliefs as one factor that is likely to help people make sense of their loss during bereavement. In addition, belief in an afterlife also helps them make sense of the loss they assert. Some of the subjects were not sure they would leave the incarceration alive and so it makes sense that this belief in God helped them make sense of the events and thus cope better.

Positive emotion for instance, hope, love and so on as well as laughter was identified as one of the pathways to resilience by Bonanno (2004). This agrees with what we found, where some of the victims of torture relied on humor to help them cope.

Taylor (1991) adds another dimension to this debate on resilience and coping. It could also be that the subjects resilience was informed by what she calls the mobilization-minimization hypothesis. When first assaulted, the subjects mobilized their array of resources psychological, spiritual and physical in order to survive. Later psychologically minimizing what was happening to them helped them cope. Taylor (1991) describes this dynamic in this way:

In summary, certain evidence concerning human and animal physiology, emotions, memory, judgment, and social functioning suggests that negative events initially mobilize and tax resources, but these same events are minimized shortly thereafter. (p.80) 


\section{Conclusion}

If resilience is more common than succumbing to trauma according to Bonanno (2004), is it not strange that we know so little about it? If we could study what he calls the resilience trajectory in detail we would unearth strategies for coping and hence resilience that would millions in our violent world, and especially so here in Africa. Individuals can be taught how to maintain psychological equilibrium even in the face of traumatic events. They would experience what Bonanno (2004) calls transcient perturbation before resuming normal physical and psychological functioning.

Kenya experienced ethnic pogroms at the beginning of 2008 yet we as a people are already 'moving on'. Might we have resilience at the level of the group? For instance, what grief work did newly independent Kenya engage in to heal people from the psychological and physical atrocities visited on them by the British colonialists? Yet we as a people have continued living and I would not say that the majority of Kenyans have PTSD. On the contrary, I would agree with Bonanno (2004) that the majority of us have shown a lot of resilience.

\section{R e f e r e n c e s}

Bonanno. G. A (2004) Loss, Trauma and Human Resilience: Have We Underestimated the Human Capacity to Thrive after extremely Aversive Events? American Psychologist, 59, 20-28

Bonanno,G.A, Rennicke,C and Dekel, S (2005) Self-Enhancement Among High Exposure Survivors of the September $11^{\text {th }}$ Terrorist Attack: Resilience or Social Maladjustment? Journal of Personality and Social Psychology, Vol.88,No.6, 984-998

Davis, G.C, Nolen-Hoeksema, S and Larson,J (1998) Making Sense of Loss and Benefiting from the Experience: Two Construals of Meaning, Journal of Personality and Social Psychology, Vol. 75, No.2. 561-574

Davis,N (1996) Once Upon a Time...Therapeutic Stories that Teach and Heal, Published by Nancy Davis Ph.D 9836 Natuk Road Burke, VA 22015 703-978-4321.

Foa, E.B and - E. A. Meadows (1997) Psychological Treatments for Post traumatic Stress Disorder: A Critical Review, Annual Review of Psychology, Vol. 48: 449-480

Klingler, P.G,(ed)(1996) Trauma: From Individual Helplessness to Group Vienna: Paul Haupt Publishers.

Maddi, S.R (2002) The Story of Hardiness: Twenty Years of Theorizing, Research and Practice, Consulting PsychologyJournal, 54, 173-185 
Maddi, S.R (2005) On Hardiness and Other Pathways to Resilience, American Psychologist Vol.60, No.7, 261-272

National Institute of Mental Health; "Facts about Post Traumatic Stress Disorder", http://www.nimh.nih.gov/ downloaded on 02/17/2006

\section{Psychology gives solace to a nation in distress}

Schut HA, - de Keijser J, - Van den Bout J, - Dijkhuis JH. - (1991) Post-traumatic stress symptoms in the first years of conjugal bereavement. Anx. Res. 4: 225- 34

Silver, R.C., Holman, A., McIntosh, D.N., Poulin, M., and Gilrivas, V. (2002) Nationwide Longitudinal Study of Psychological Responses to September 11, Journal of the American Medical Association, Vol. 228, pp. 1235-1244

Taylor, S.E (1991) Asymmetrical Effects of Positive and Negative Events: The MobilizationMinimization. Hypothesis, Psychological Bulletin, Vol.110,No, 1, 67-85

Taylor, S.E (1983) Adjustment to Threatening Events: A Theory of Cognitive Adaptation, Amereican Psychologist, 38, 1161-1173

Taylor, S.E, Kemeny,M.E, Gruenewald, T,L, REE, G.M (2000) Psychological Resources, Postive Illusions and Health, American Psychologist, Vol.55,No1,99-109.

National Institute of Mental Health, "Helping children cope with violence and disaster: What parents can do", http://www.nimh.gov, 2007

Aldwin, M, Levenson, R. M. \& Spiro III (1994), A Vulnerability and Resilience to Combat Exposure: Can Stress Have a Lifelong Effect, Pyschology and Aging Vol. 9. 1:34-44

Kulka, R. A., Jordan. B. K. Hough, R. A. (1992), The Prevalence of Lifelong and Partial Post-traumatic Stress Disorder in Vietnam Theatre Veterans, Journal of Traumatic Stress. Vol. 5. 23 